\title{
New Developments on Enzymatic treatments on Cellulosic Fibers
}

\author{
Su-yeon Kim ${ }^{1}$, Andrea Zille ${ }^{1}$, Andreia Vasconcelos ${ }^{1}$, \\ Artur Cavaco-Paulo ${ }^{1}$ * \\ ${ }^{1}$ University of Minho, Department of Textile Engineering, 4800-058 \\ Guimarães, Portugal \\ "Author for correspondence: University of Minho, Department of Textile \\ Engineering, Campus de Azurém, 4800-058 Guimarães, Portugal. Tel: +351 \\ 253510271 Fax: +351 253 510293, artur@det.uminho.pt
}

\begin{abstract}
In this review, we focused on the recent and non-conventional enzyme bioconversions of cellulosic fibers. Cellulosic fibers are the largest market of textile industry and also represent the most successful market for enzymes base processes in the textile area. The new enzyme developments presented on this paper include the strength recovering in resin-crosslinked fabrics, phosphorylation for better antiflame retardancy, coating and funcionalization of cellulosic fabrics.
\end{abstract}

The processing of cellulosic fibers is generally performed at alkaline conditions. This is mainly due to the free hydroxyl groups of 1-4, B-D glycosodic units that only become ionized at high $\mathrm{pH}$ values. In general all 
treatments done at high $\mathrm{pH}$ 's need further neutralization washing steps consequently and large amount of water consumption. The reactive dyeing of cellulosic fibers is a well known example of this type of treatments. The application of biotechnology to process cellulosic fibers could provide an alternative option for its modifications at milder conditions.

The use of enzymes in textile processing has been applied since middle of 19 th century when malt extract was used to remove amlylaceous sizes before dyeing and printing (1). Enzymatic processes have been developed for wet processing of textile goods in wide ranging operations from cleaning preparations to finishing processes. The possibility of replacing alkaline scouring with the enzymatic decomposition of non-cellulosic impurities and increasing the wettability of the textile material in using various types of enzyme-cellulase, pectinase, lipases and proteases under different applications have been studied widely (2). Enzymes have their optimum condition of temperature and $\mathrm{pH}$ (1). Therefore the enzymatic treatment temperature and $\mathrm{pH}$ control is important from the point of view of getting the maximum activity from enzymes. In the following chapters we will describe the new enzymatic methods to hydrolyze crosslinks, phosphorylate, removal of cellulose and coating with the use of several enzymes like lipase, protease, cellulase and laccase.

\section{Lipases and Proteases to Improve the Mechanical Characteristics of Durable Press Finished Cotton Fabrics}

Durable press finishing processes are widely used in the textile industry to impart wrinkle-resistance to cotton fabrics and garments. However formaldehyde is released during the fixation procedure. Therefore in the last years many efforts have been made to develop formaldehyde-free crosslinking agents. For this purpose polycarboxylic acids and N-hydroxymethy acryl amide ware chosen as most promising formaldehyde-free agents. It is well known drawback of any crease-resistance treatment on cotton fabrics that the improvement of the dimensional stability and wrinkle resistance is always correlated with severe loss of mechanical strength of treated fabrics (3). The fabric strength loss caused by crosslinking is described as a reversible process and could be restored by chemical hydrolysis (4). Milder, low concentration enzymatic process could be performed onto the textile in order to reduce the strength loss of crosslinked cotton.

The application of lipase restores partially the strength loss of the fabrics due to the polycarboxylic crosslinking by hydrolysis of the ester linkages. The 
lipase treatment improved the tensile strength with up $10 \%$, causing just a $4 \%$ of alteration of crease-resistance on the fabrics (4). Proteases were applied to recover the tensile strength loss of $\mathrm{N}$-hydroxymethylacrylamide crosslinked cotton fabrics. The hydrolysis using protease of the amide bond in the crosslinked cellulose resulted in about $15 \%$ strength loss recovery coupled with up to $8 \%$ decrease of crease-resistance effect (5). In the conventional alkaline hydrolysis is obtained a diminution of the wrinkle - resistance of the fabrics as well as a diminution of the strength loss. Most of lipases are serine hydrolases, containing a serine residue in their active site and forming an intermediate acyl enzyme substitute complex. The protease hydrolysis of the amide bonds is processed through two steps, acylation and deacylation. And the formation of acyl intermediate is the rate-limiting step.

\section{Phosphorylation of cotton cellulose}

The phosphorus contents of polymers play an important role in flame retardance. Phosphorus containing compounds usually act in solid phase of burning materials. When heated, the phosphorus reacts to give a polymeric form of phosphoric acid $\left(\mathrm{PO}_{3}{ }^{2-}\right)$. Chemical phosphorylation is usually rather complicated process, requiring several protection and deprotection steps (6). But the using enzyme process can make synthesis more efficient and eliminate many of these steps.

The enzymatic application of phosphorus on cellulosic fiber as flameresistance function has been studied in several reserches: Hexokinase enzymes catalyze phosphoryl transfer from adenosine-5' -triphosphate (ATP) to the 6hydroxyl group of a number of furanose and pyranose compounds. The new biosynthesis process for the phosphorylation of cotton cellulose with the enzyme hexokinase in the presence of phosphoryl donor ATP was studied and expected reaction mechanism was showed in figure 1 (7). The results of the burning experiments shown significant flame retarding effect on the enzymatic treated fabrics. 


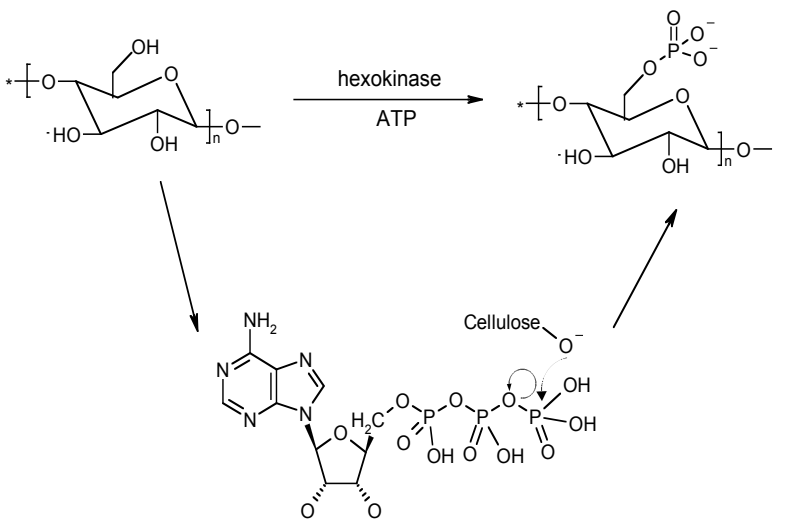

Figure 1. Mechanism of hexokinase-catalysis cellulose phosphorylation. (Reproduced with permission from reference 7.)

\section{Production of light weight PES fabrics}

Due to fashion tendencies there is a market for light - weight polyester fabrics that cannot be produced by the normal power looms. Therefore, a possible alternative is the production of fabrics from polyester blended with another fiber that is later on eliminated by chemical treatments. The most common are the polyester blends with cellulosic fibers. In this case the cellulose is normally removed with a $75 \%(\mathrm{v} / \mathrm{v})$ sulfuric acid solution. Acid hydrolysis of cellulose is a fast and cheap process but it presents the drawback of not being ecological. Thus, enzymatic hydrolysis is a cleaner alternative that takes place at atmospheric pressure, moderate temperatures and mild $\mathrm{pH}$ conditions. In nature, the cellulose degradation is performed by cellulases of bacterial or fungal origin. The efficient degradation of this substrate requires the combined action of several types of cellulases: endoglucanases (EC 3.2.1.4) that produce new ends randomly within the polysaccharide chain; cellobiohydrolases (EC 3.2.1.91) which release cellobiose units from the cellulose chain ends and $\beta$-glucosidases (EC 3.2.1.21) that convert cellobiose into glucose. Cotton fibers can be completely converted into microfibrilar material by combined action of enzyme hydrolysis and strong mechanical effects in short periods of time. The 
production of insoluble material is dependent on the level of beating effects present inside the treatment pots (8).

The production of light-weight polyester fabrics was investigated by enzymatic removal of the cellulose from a polyester/cotton blended fabric. The removal of cotton from the blended fabric yields more than $80 \%$ of insoluble microfibrilar material by combined action between high beating effects and cellulose hydrolysis. In such a process, it was verified that other major features like bath ratio, enzyme dosage and treatment time play an important role on the conversion of cotton fibers into microfibrilar material(9).

\section{Laccases application on the fabrics expecting different effects}

Laccases are multi-copper enzymes catalyze the oxidation of a wide range of inorganic and organic substances using oxygen as an electron acceptor (10). Laccases are able to catalyze the transformation of various aromatic compounds, specifically phenols and anilines, through an oxidative coupling reaction of concomitantly reducing molecular oxygen to water (11-13) and the mechanism of enzymatic polymerization is shown in Figure 2. Depending on the 'R-group' different properties can be delivered to the fiber.

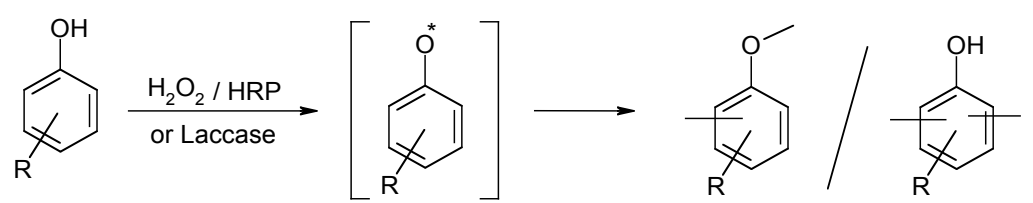

Figure 2. Laccase catalyze polymerization of phenolic compounds (Reproduced with permission from reference 14.)

Solution polymerization of phenolic compound by enzyme in the presence of cellulosic fiber is done to produce polymer coated materials. Many enzymatically polymerized phenolic compounds tend to have a characteristic color because polyphenol forms a big conjugated structure along the main chain (14). Laccase can be used bleaching process of cellulosic fiber materials. The 
short time of the enzymatic pre-treatment is sufficient to enhance fabric whiteness, renders this bio-process suitable for continuous operations. This lowenzyme consuming laccase pre-treatment at mild conditions can reduce significantly the hydrogen peroxide dosage in subsequent chemical bleaching (15).

In case of cotton colorization by laccase, the cotton fabric is previously treated dyeing and functionalizaton and the amino groups are formed and coupled with polymer. The products obtained from the coupling processes of aminized cellulose with products obtained from catechol oxidation by laccase are identified by LC/MS analysis. This mechanism and the products confirmed by $\mathrm{LC} / \mathrm{MS}$ analysis is shown in Figure 3.

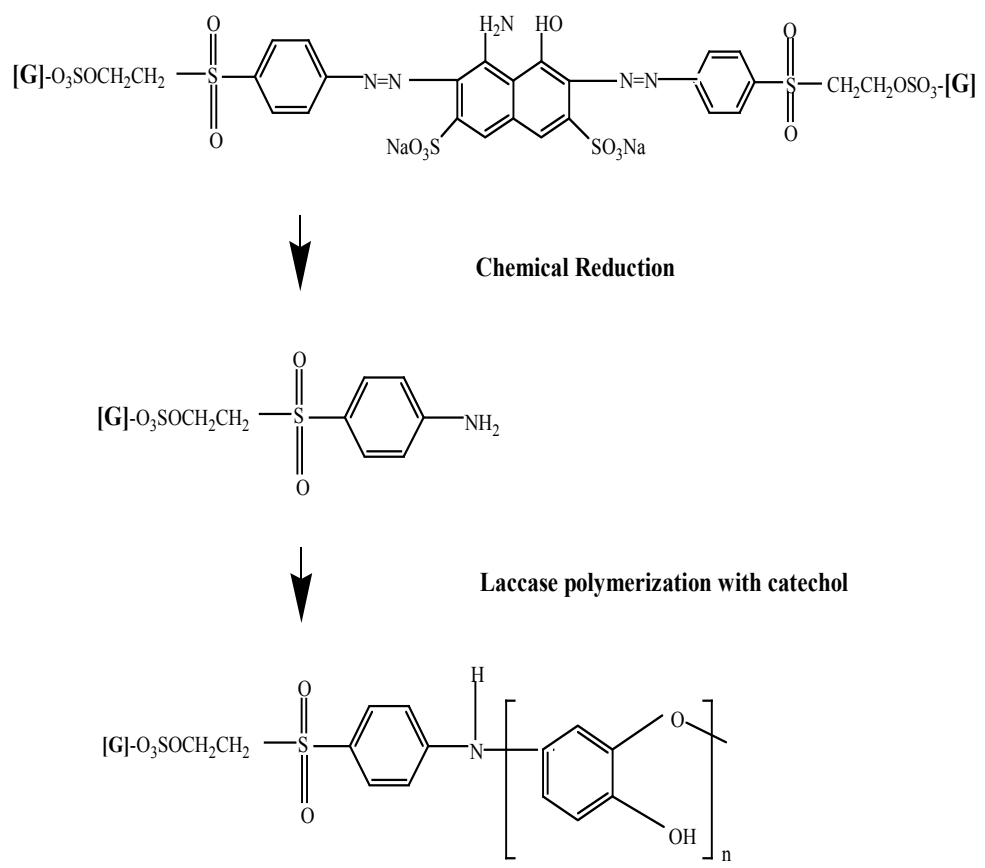

Confirmed by LC/MS analysis

Figure 3. Chemical mechanism of colorization of cotton cellulose fiber by laccase and the products of reaction were confirmed using LC/MS analysis com 


\section{References}

1. Aly, A. S.; Moustafa, A. B. J. Cleaner Production. 2004, 12, 697.

2. Cavaco-paulo, A.; Gubitz, G. Textile processing with enzymes; Woodhead Publishing Ltd: Cambridge, England, 2003; p 72.

3. Sricharussin, W.; Ryo-Aree, W.; Intasen, W.; Poungraksakirt, S. Text. Res. J. 2004, 74, 475.

4. Tzanov, T.; Stamenova, M.; Betcheva, R.; Cavaco-Paulo, A. Macromol. Mater. Eng. 2002, 287, 462.

5. Stamenova, M.; Tzanov, T.; Betcheva, R.; Cavaco-Paulo, A. Macromol. Mater. Eng. 2003, 288, 71.

6. Edwords, J. V.; Yager, D. R.; Cohen, I. K.; Diegelmann, R. F.; Montante, S.; Bertoniere, N.; Bopp, A. F. Wound Repair Regen. 2001, 1, 50.

7. Tzanov, T.; Stamenova, M.; Cavaco-Paulo, A. Macromol. Rapid. Commun. 2002, 23, 962 .

8. Morgado, J.; Cavaco-Paulo, A.; Rousselle, M. Text. Res. J. 2000, 70, 696.

9. Vasconcelos, A.; Cavaco-Paulo, A. Cellulose. 2006, in press.

10. Zille, A.; Gornacka, B.; Rehorek, A. Appl. Environ. Microbiol. 2005, 71, 6711.

11. Zille, A.; Munteanu, F.; Gubitz, G.; Cavaco-Paulo, A. J. Mol. Catal. B: Enzym. 2005, 33, 23.

12. Guresir, M.; Akatas, N.; Tanyolac, A. Prog. Biochem. 2005, 40, 1175.

13. Gianfreda, L.; Sannino, F.; Rao, M. A.; Bollag, J.-M. Water Res.. 2003, 37, 3205.

14. Shin, H.; Gubitz, G.; Cavaco-Paulo, A. Macromol. Mater. Eng. 2001, 286, 691.

15. Tzanov, T.; Basto, C.; Gubitz, G.; Cavaco-Paulo, A. Macromol. Mater. Eng. 2003, 288, 807. 